University of Wollongong

Research Online

Australian Institute for Innovative Materials -

Papers

Australian Institute for Innovative Materials

$1-1-2018$

\title{
A smart cyto-compatible asymmetric polypyrrole membrane for salinity power generation
}

Changchun $\mathrm{Yu}$

University of Wollongong, cy470@uowmail.edu.au

Xuanbo Zhu

Chinese Academy Of Sciences

Caiyun Wang

University of Wollongong, caiyun@uow.edu.au

Yahong Zhou

Chinese Academy Of Sciences

Xiaoteng Jia

University of Wollongong, xj916@uowmail.edu.au

See next page for additional authors

Follow this and additional works at: https://ro.uow.edu.au/aiimpapers

Part of the Engineering Commons, and the Physical Sciences and Mathematics Commons

Research Online is the open access institutional repository for the University of Wollongong. For further information contact the UOW Library: research-pubs@uow.edu.au 


\title{
A smart cyto-compatible asymmetric polypyrrole membrane for salinity power generation
}

\author{
Abstract \\ Inspired by biological channels that occur in nature, smart biomimetic nanofluidic systems have been \\ built to enable salinity power harvesting. However, most of these smart membranes are composites \\ containing two incompatible components that require sophisticated fabrication techniques, thus limiting \\ practical applications. Here, a single component polypyrrole membrane has been developed via a simple \\ self-assembly process. The membrane provides asymmetric wettability on either side, cytocompatibility \\ and an electrochemically tuneable ionic conductance. The ability of this membrane to capture energy \\ arising from a salinity gradient has been demonstrated. The system can provide a stable current density \\ over $16 \mathrm{~h}$ using artificial seawater and river water to provide the salinity gradient, and an energy density of \\ $1.4 \mathrm{Wh} / \mathrm{m} 2$ was obtained. The cytocompatibility and ability to generate salinity power make this \\ membrane a promising material for biomimetic applications.

\section{Disciplines} \\ Engineering | Physical Sciences and Mathematics

\section{Publication Details} \\ Yu, C., Zhu, X., Wang, C., Zhou, Y., Jia, X., Jiang, L., Liu, X. \& Wallace, G. G. (2018). A smart cyto-compatible \\ asymmetric polypyrrole membrane for salinity power generation. Nano Energy, 53 475-482.

\section{Authors} \\ Changchun Yu, Xuanbo Zhu, Caiyun Wang, Yahong Zhou, Xiaoteng Jia, Lei Jiang, Xiao Liu, and Gordon G. \\ Wallace
}




\title{
A Smart Cyto-compatible Asymmetric Polypyrrole Membrane for Salinity Power
}

\section{Generation}

Changchun $\mathrm{Yu}^{1}$, Xuanbo Zhu ${ }^{2}$, Caiyun Wang ${ }^{1 *}$, Yahong Zhou ${ }^{2 *}$, Xiaoteng Jia ${ }^{1}$, Lei Jiang ${ }^{2}$, Xiao Liu ${ }^{l}$, Gordon G. Wallace ${ }^{1 *}$

${ }^{1}$ Intelligent Polymer Research Institute, ARC Centre of Excellence for Electromaterials Science, University of Wollongong, Australia

${ }^{2}$ CAS Key Laboratory of Bio-inspired Materials and Interfacial Science Technical Institute of Physics and Chemistry, Chinese Academy of Sciences, Beijing, P. R. China

Email: caiyun@uow.edu.au; zhouyh@iccas.ac.cn; gwallace@uow.edu.au

\begin{abstract}
Inspired by biological channels that occur in nature, smart biomimetic nanofluidic systems have been built to enable salinity power harvesting. However, most of these smart membranes are composites containing two incompatible components that require sophisticated fabrication techniques, thus limiting practical applications. Here, a single component polypyrrole membrane has been developed via a simple self-assembly process. The membrane provides asymmetric wettability on either side, cytocompatibility and an electrochemically tuneable ionic conductance. The ability of this membrane to capture energy arising from a salinity gradient has been demonstrated. The system can provide a stable current density over $16 \mathrm{~h}$ using artificial seawater and river water to provide the salinity gradient, and an energy density of $1.4 \mathrm{Wh} / \mathrm{m}^{2}$ was obtained. The cytocompatibility and ability to generate salinity power make this membrane a promising material for biomimetic applications.
\end{abstract}




\section{Graphic Abstract}

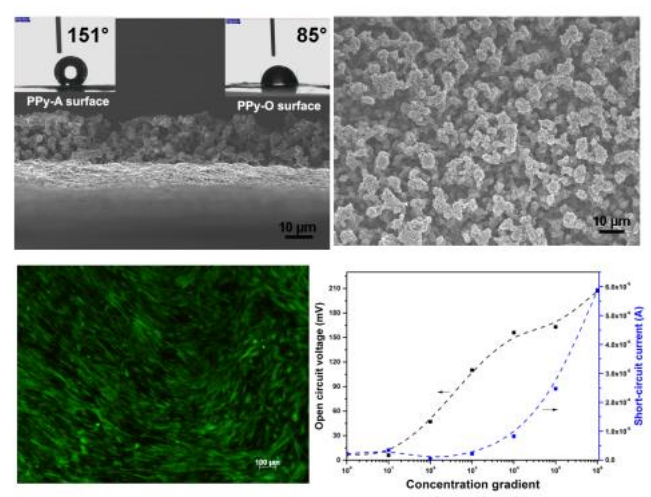

Keywords: smart membrane, asymmetric properties, polypyrrole membrane, salinity gradient energy.

\section{Introduction}

Salinity gradient power is a clean and sustainable form of energy that can be captured from water via partitioning two aqueous solutions of different salinities across a membrane [1]. The membranes used to capture this type of energy at normal pressure screen the passing ions, resulting in a net electrical current. They commonly feature a nano-porous structure with a specific surface charge (cationic or anionic) [2, 3]. Smart membranes with artificial biological ion channels are capable of reproducing the biological energy conversion process based on a salinity gradient as well as making biomimetic response by responding to environmental stimuli, such as $\mathrm{pH}$, temperature, light or electrical potential [4-7]. Such membranes have also been used for nanofluidic devices, biosensing and drug delivery [8-10]. These nanochannels containing membranes are commonly fabricated by a self-assembly process, ion track etching, or electrochemical etching with limited scope for scale-up [11-13]. Typically the "smart" nanochannels can be either directly fabricated with functional materials or indirectly by surface modifying these nanochannels with functional molecules [14]. A single component membrane is highly desirable for simplicity. 
Polypyrrole (PPy) possesses the properties of ionic as well as electronic conductivity [15]. It has been used extensively in bioengineering and energy storage owing to its biocompatibility and electroactivity $[16,17]$. The defects in its $\pi$-electron system (polarons, bipolarons) can act as positive charge carriers favouring the conduction of mobile anions within the polymer backbone [18]. PPy has been used previously as an ion-exchange membrane with ion transport controllable via an externally applied potential $[19,20]$. With ion selectivity, PPy has the potential to apply for salinity power generation. To date, heterogeneous membranes incorporating PPy as a component, such as alumina/PPy, poly (acrylamide-coacrylicacid)/PPy membrane, have been developed to realise the smart $\mathrm{pH} /$ light or electro/pH modulated ion transport $[21,22]$. In these studies, the PPy layer was electrodeposited on a pre-fabricated nanoporous scaffold. The inherent incompatibility between two components may lead to a phase separation [23]. It would be highly desirable if a one component PPy membrane with an asymmetric porous structure could achieve all these smart functions. However, no such membrane has been demonstrated.

Here, we report a smart single component porous polypyrrole membrane with an asymmetric structure prepared via a facile self-assembly process. It is a biocompatible substrate for Adipose-derived stem cell adhesion and proliferation. This membrane was used for salinity gradient power generation with an electrochemically tuneable ionic conductance as well. It can be anticipated that this single component PPy membrane would be a promising smart material for energy harvesting and biomimetic applications.

\section{Experimental}

Materials: Pyrrole, ferric chloride hexahydrate and Tween-80 were obtained from SigmaAldrich. PBS solution was prepared by dissolving a PBS tablet in $200 \mathrm{~mL}$ deionized water (pH 7.4). Gibco Dulbecco's Modified Eagle's Medium (DMEM), Fetal bovine serum (FBS), penicillin-streptomycin, calcein and propidium iodide (PI) were obtained from Life 
Technologies. Commercial human adipose-derived stem cells (hADSCs) were obtained from Lonza Company.

Fabrication: The free-standing PPy membrane was synthesized at an aqueous/organic interface following the reported procedures with some modifications [24]. Briefly, pyrrole was dissolved in chloroform to form the organic phase $(0.1 \mathrm{M}, 10 \mathrm{ml}) . \mathrm{FeCl}_{3}(0.15 \mathrm{M})$ and Tween-80 (0, 0.5, 2, $4 \mathrm{~g} / \mathrm{L})$ were added into Milli-Q water $(10 \mathrm{~mL})$ to form the aqueous phase. These two solutions were pre-cooled in an ice-salt bath (weight ratio of ice to salt was 30:1). Then the aqueous solution was gently transferred onto the top of the organic phase. The reaction was initiated when PPy monomer encountered $\mathrm{FeCl}_{3}$, and the reaction proceeded for 24 hours in the ice-salt bath. The formed film was washed alternately with water and ethanol, then dehydrated using ethanol and dried in air.

Cell work: PPy membranes were sterilised by soaking in ethanol for $30 \mathrm{~min}$ and exposed in UV-light for $20 \mathrm{~min}$. Then they were placed into a 24-well polystyrene cell culture plate and soaked overnight with culture medium, followed by rinsing with PBS twice. Adipose-derived stem cells (hADSCs) were seeded in the well with an initial density of $2 \times 10^{4}$ cells $/ \mathrm{cm}^{2}$. Cell viability and proliferation ability were measured by PrestoBlue (Life Technology). Specifically, at day 2, 5, 7, 10, 14 and 21, cells were incubated in $10 \%$ Prestoblue for $1 \mathrm{~h}$. Fluorescence was measured by using a plate reader with a $544 \mathrm{~nm}$ excitation filter and a $590 \mathrm{~nm}$ emission filter. Cells were visualized using Live/Dead (calcein-AM/PI) staining with $2 \mu \mathrm{m}$ Calcein AM and $4 \mu \mathrm{M}$ PI in PBS. Images were obtained using a ZEISS Axio Imager microscope (Carl Zeiss). For SEM imaging, the hADSCs were fixed in $3.7 \%$ paraformaldehyde for $1 \mathrm{~h}$ at room temperature, followed by a freezing process in liquid nitrogen and a subsequent freeze-dry process.

Characterisation: Surface morphology and cross-sectional view were investigated by field emission scanning electron microscopy (JEOL JSM-7500FA). Cyclic voltammetry tests were 
performed with an electrochemical workstation (CHI 650D). Impedance spectra were measured using a Gamry EIS 3000 system over a frequency range of $100 \mathrm{kHz}$ to $0.01 \mathrm{~Hz}$ with an $\mathrm{AC}$ perturbation of $10 \mathrm{mV}$ at the open-circuit potential. Electrical measurements were conducted by mounting the PPy membrane with a solution contact area of $3.14 \mathrm{~mm}^{2}$ (e.g., diameter $2 \mathrm{~mm}$ ) between two halves of a custom-made electrochemical cell where $2 \mathrm{~mL}$ electrolyte was added into each half-cell. The current-voltage was recorded by a Keithley picoammeter.

\section{Results and discussions}

The PPy membrane was fabricated using interfacial polymerization in a salt-ice bath (Figure 1A). Reactants (pyrrole and oxidant $\mathrm{FeCl}_{3}$ ) dissolved in each of the immiscible phases react at the interface to form the insoluble membrane [25]. The pyrrole monomer diffused into the water layer and seated at the hydrophobic tail of surfactant molecules through secondary forces such as $\pi-\pi$ interactions and hydrogen-bonding [26]. The surfactant Tween-80 molecules $(0.5 \mathrm{~g} / \mathrm{L})$ aggregated into core-shell cylindrical micelles in which four long chains entangled with one another through intra- and inter- molecular interactions at the applied condition [27]. The unidirectional growth of PPy proceeded with the continuous supply of pyrrole monomer and created an interconnected 3D porous structure. A black membrane with a diameter of $4 \mathrm{~cm}$ (size of the reaction container) was formed at the interface after $24 \mathrm{~h}$. This free-standing film was robust, demonstrating a conductivity around $200 \mathrm{~S} / \mathrm{m}$ and a thickness of $20 \mu \mathrm{m}$ (Figure 1B). It displayed an asymmetric structure as shown in the cross-sectional view in Figure 1C: a uniformly interconnected 3D porous structure on the PPy-A surface (Figure 1D), and a planar macroporous structure on PPy-O surface (Figure 1E). More specifically, PPy-A surface displayed a gradient pore distribution with pore size in a range of $1 \sim 30 \mu \mathrm{m}$, while the average pore size of the PPy-O surface membrane was around $1.3 \mu \mathrm{m}$ 
(Figure S1). Aggregated PPy granules can be clearly observed, and they were stacked up to tens of micrometres.

Without the presence of surfactant, the produced PPy membrane was very thin and transparent black (Figure S2A), displaying an integrated fiber network with large amount of pores in big sizes (up to $20 \mu \mathrm{m}$ ). This is attributed to the limited amount of pyrrole available for the polymerization. When the surfactant concentration was increased to $2 \mathrm{~g} / \mathrm{L}$ and $4 \mathrm{~g} / \mathrm{L}$, larger vesicles were formed (Figure S2B, S2C). The increased volumes and numbers of micelles induced a simple merging mutually because of the lowered interfacial tension, following the PPy growth in this merged micelle model [28]. When the reaction temperature was elevated (in an ice bath), the produced PPy membrane became much thicker $(\sim 100 \mu \mathrm{m}$, Figure S3). These results clearly demonstrate that formation of this porous PPy membrane can be easily modulated by controlling the used surfactant and temperature. It is also reasonable to deduce that the formed structure can be further tuned with different types of surfactant with varying micelle shapes. It should be noted that this facile chemical polymerization method can be easily scaled up.

This PPy film demonstrated the characteristic bands of PPy in the FTIR spectrum (Figure S4): the band at $925 \mathrm{~cm}^{-1}$ is attributed to $\mathrm{C}-\mathrm{H}$ wagging [29]; band at $1565 \mathrm{~cm}^{-1}$ corresponds to $\mathrm{C}=\mathrm{C}$ stretching; and band at $1311 \mathrm{~cm}^{-1}$ represents $\mathrm{C}-\mathrm{N}$ bonds [30]. The surface in contact with the aqueous or organic phase is referred to as PPy-A and PPy-O, respectively. Those two faces of this film displayed different wettability as evidenced by contact angles observed: $\sim 151^{\circ}$ on the hydrophobic PPy-A surface (insert image in Figure $1 \mathrm{D}$ ); and $\sim 85^{\circ}$ on the hydrophilic PPy-O surface (insert image in Figure 1E). The wettability of a solid surface is governed by both chemical composition and microstructure [31]. In addition, an isotropic wettability was observed on the PPy-A surface where water droplets could roll in different directions with equal ease, evidencing a uniform surface (Movie S1). Such a film with 
asymmetric wettability would find broad applications; such as micro-fluidic devices, liquid transfer, and bio-inspired systems [32].

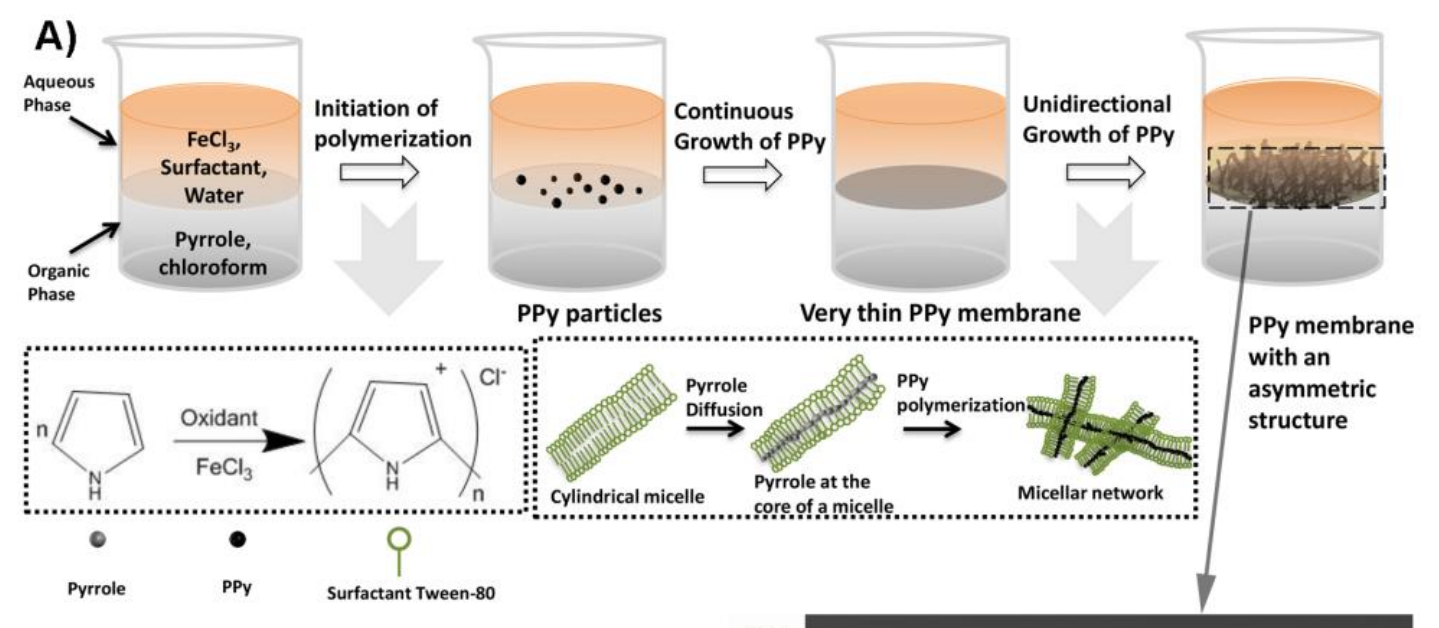

B)
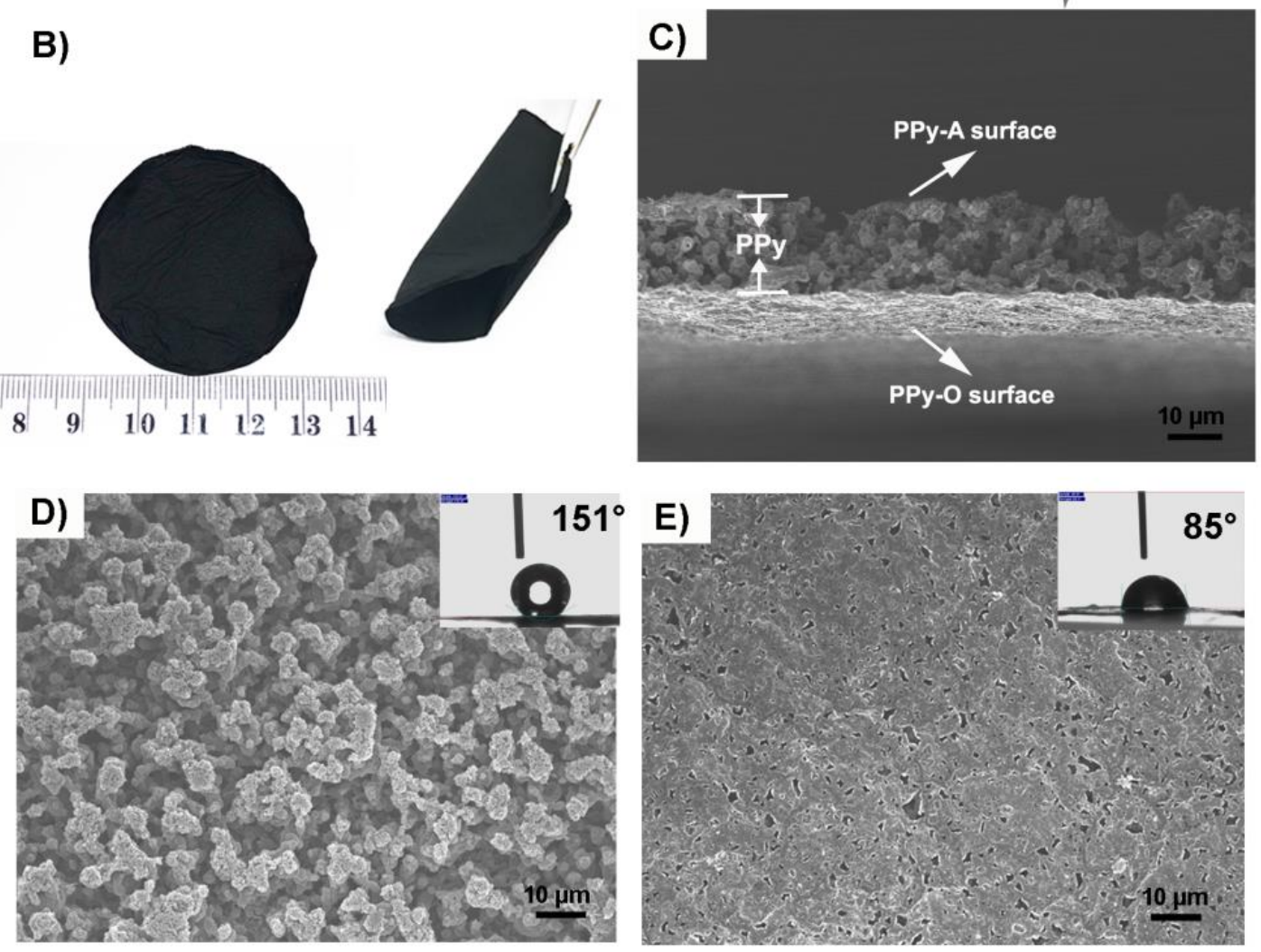

Figure 1 Polypyrrole membrane with asymmetric structure was fabricated via interfacial polymerization: A) Schematic diagram of the PPy growth; B) Photograph of a PPy membrane with a diameter of $4 \mathrm{~cm}$ and a demonstration that this film is robust by bending to $180^{\circ}$ with a tweezer, and C) SEM images of a cross-sectional view of this PPy membrane; D) SEM 
images of PPy-A surface and E) PPy-O surface (inset images: contact angle of water droplet on the corresponding surfaces).

An electrochemical system (Figure 2A) was used to examine the ionic transport properties of this PPy membrane by measuring the transmembrane ionic current. The electrode used was $\mathrm{Ag} / \mathrm{AgCl}$, and was placed on each side of the membrane for the measuring. The positively charged backbone of PPy attracted counterions $\mathrm{Cl}^{-}$to ensure the electroneutrality. The electrochemical potential difference between the solutions is the driving force for ion transport. As a result, electrons can be transferred from one electrode to another via an external electrical circuit, generating an electrical current [33]. In short, the ion flux was driven by chemical potential through the positively charged PPy pores, forming diffusion current composed of mostly negatively charged ions. The electrolyte concentration at the PPy-O side was fixed at $1 \mu \mathrm{M}$, and that at the PPy-A side was gradually elevated from $1 \mu \mathrm{M}$ to $1 \mathrm{M}$. The voltage generated was in the range of several to hundreds of $\mathrm{mV}$ (Figure $\mathrm{S} 5, I-V$ response), comparable to the reported result for an ionic diode carbon membrane [34]. The redox reactions $\left(\mathrm{Ag}+\mathrm{Cl}^{-} \Leftrightarrow \mathrm{AgCl}+\mathrm{e}\right)$ on the electrodes contributed to the obtained potentials as well. An equivalent circuit of ion diffusion through the membrane is shown in Figure S6. The electric potential generated in the micropores is given by $V=V_{\text {out }}-V_{\text {redox }}$ , where $\mathrm{V}_{\text {out }}$ is the voltage output read from a source meter, $\mathrm{V}_{\text {redox }}$ is the potential difference between two $\mathrm{Ag} / \mathrm{AgCl}$ electrodes that was cited from the reference [34]. All these three potentials were listed in Table S1. The measured potential reached a high potential of 207 $\mathrm{mV}$ at a gradient ratio of $10^{6}$ (Figure $2 \mathrm{~B}$ ), where the potential generated in the micropores was $93 \mathrm{mV}$. For the concentration gradients lower than $10^{-6} / 10^{-3}$, the membrane showed much lower potentials and thus were not shown, which may be due to its poor ion selectivity. The ion selectivity of a membrane can be characterised with transference number, that is calculated by referring to the formula $t_{n}=\frac{1}{2}\left(\frac{V_{\text {diff }}}{V_{\text {redox }}}+1\right)[35,36]$. It is noticed that the 
transference number varied with the increased salt gradients, and it displayed the lowest value $t_{n}$ of 0.61 at the lowest solution gradients of $10^{-6} / 10^{-3}$ (Table S2). It is different from the commonly reported trend that the transference number of nanoporous membrane decreases with the increasing ionic concentration as the surface charges are screened by the ions bearing opposite charge polarity [37]. This is attributed to surface charge density of the membrane which is modulated with osmotic pressure between the polymer and electrolyte [38-40], since PPy is able to afford charge transport both ionically and electronically allowing the in and out movement of the doped ions [41, 42].

In this electrochemical system, a potential of $163 \mathrm{mV}$ was obtained from the $0.1 \mathrm{M} / 1 \mu \mathrm{M}$ gradient when high salt concentration solution was placed at the hydrophobic PPy-A side, much higher than that $69 \mathrm{mV}$ from the reverse concentration gradient (Figure S7). It also means that the diffusion electric filed was stronger from PPy-A surface to PPy-O surface. It may be explained by the difference in charge density at these two faces: PPy-A surface might be at a higher doped state with a higher charge density, since sufficient oxidant $\mathrm{FeCl}_{3}$ was available for the polymerization in the aqueous phase. In addition, it is favourable for ions to transfer from PPy-A surface to PPy-O surface as water tends to transfer from the hydrophobic side to the hydrophilic side $[43,44]$. Thus the difference in the charge density as well as surface structure render an ion permselectivity. Such a selective ion diffusion will endow this PPy membrane with a broad range of applications such as charge separation process, and nanofluidic sensing devices.

The ionic transport property of this PPy membrane in different concentrations of $\mathrm{KCl}$ solution was examined (Figure S8). The conductance decreased nonlinearly with the concentration and notably deviated from the bulk value from $10^{-3} \mathrm{M}$, shown as the dashed line (a linear trend of ionic conductance with the decreased concentration), indicating 
surface-charge-governed ion transport (Figure 2C). At low concentrations, the water/ion ratio makes the average distance between ions quite high, which enables ions to redistribute realising effective screening [45]. The conductance was governed by the surface charge density inside the pores when the Debye screening length (24 nm for $10^{-3} \mathrm{M} \mathrm{KCl}$ electrolyte, Supporting information) increased to value comparable to the pore size at low solution concentration [35]. It is also noticed that the conductance displayed a sharp conductance drop again at $10^{-6} \mathrm{M}$. It might be explained by that large amount of doped chlorine ions in PPy membrane diffused into this extremely low electrolyte, leading to greatly decreased ion selectivity as discussed above.

The harvested power which is consumed on the electric load can be calculated as $\mathrm{P}_{\text {out }}=\mathrm{I}^{2} \times \mathrm{R}$, where I is the electric current through the resistor. The power density generated from a gradient using artificial seawater $(0.5 \mathrm{M} \mathrm{NaCl})$ and river water $(0.01 \mathrm{M} \mathrm{NaCl})$ reached a peak value of $0.087 \mathrm{~W} / \mathrm{m}^{2}$ at an external resistance of $\sim 5 \mathrm{~K} \Omega$ (Figure 2D). A current density of 2 $\mathrm{A} / \mathrm{m}^{2}$ was generated and remained stable during the monitored time of $16 \mathrm{~h}$, affording an energy density of $1.4 \mathrm{Wh} / \mathrm{m}^{2}$ (Figure S9). The ability of component PPy membrane to capture salinity gradient power is attributed to its ion permselectivity, and the preferred ion transportation within the asymmetric structure. It should be noted that this PPy membrane is composed of only one component and can be easily fabricated via a chemical synthesis route, which is suitable for large scale production $[46,47]$.

The generated power density $0.087 \mathrm{~W} / \mathrm{m}^{2}$ is lower than the results reported for heterogeneous membranes (carbon/alumina, engineered polymer polyphenylsulfone/GO) due to large pores inside the film that compromises the ion selectivity $[34,48]$. Nevertheless, it's higher than the reported green energy $\left(3.89 \times 10^{-5} \mathrm{~W} / \mathrm{m}^{2}\right)$ generated by a graphene/humic acid concentration cell [49]. We cannot make the comparison with the heterogeneous membranes with a layer of PPy coating $[21,22]$, since no salinity power density was reported. It should 
be mentioned that this power was generated within the gradient of $0.01 \mathrm{M} / 0.5 \mathrm{M}$, a concentration gradient similar to that $\mathrm{Cl}-(\sim 20)$ in the body fluid. A power of $35 \mu \mathrm{W}$ can be generated from this membrane in a size of $2 \mathrm{~cm} \times 2 \mathrm{~cm}$ same as that reverse electrodialysis system used for drug delivery [50]. This power is also sufficient to drive the implantable medical devices with power requirement in the level of $\mu \mathrm{W}-\mathrm{mW}$ such as pacemaker [51]. It clearly demonstrates that this membrane has the potential for biomimetic applications. Moreover, at this gradient of $0.01 \mathrm{M} / 0.5 \mathrm{M}$, this system could generate a potential of $37 \mathrm{mV}$, larger than some bioelectric signals such as an electromyogram (less than $10 \mathrm{mV}$ ) [52].

Similar to the electric eel whose electric organ consists of stacks of electrocytes linked in series and parallels [53], the generated power density from this PPy membrane may be enhanced by assembling single cells in series. The stacked PPy membranes build up voltage and the working area is enlarged to promote the total ionic flux [53]. It has been demonstrated by Taek Dong Chung .etc that by useing increased pairs of the ion exchange membrane, the voltage is enhanced and the reverse electrodialysis system successfully facilitate the transdermal penetration of ionic drug in vitro and in vivo[50]. Improvement may also be achieved by using a heterogeneous membrane by combining a negatively charged membrane such as graphene oxide (GO) to realize a rectification effect for regulating ion flux. 

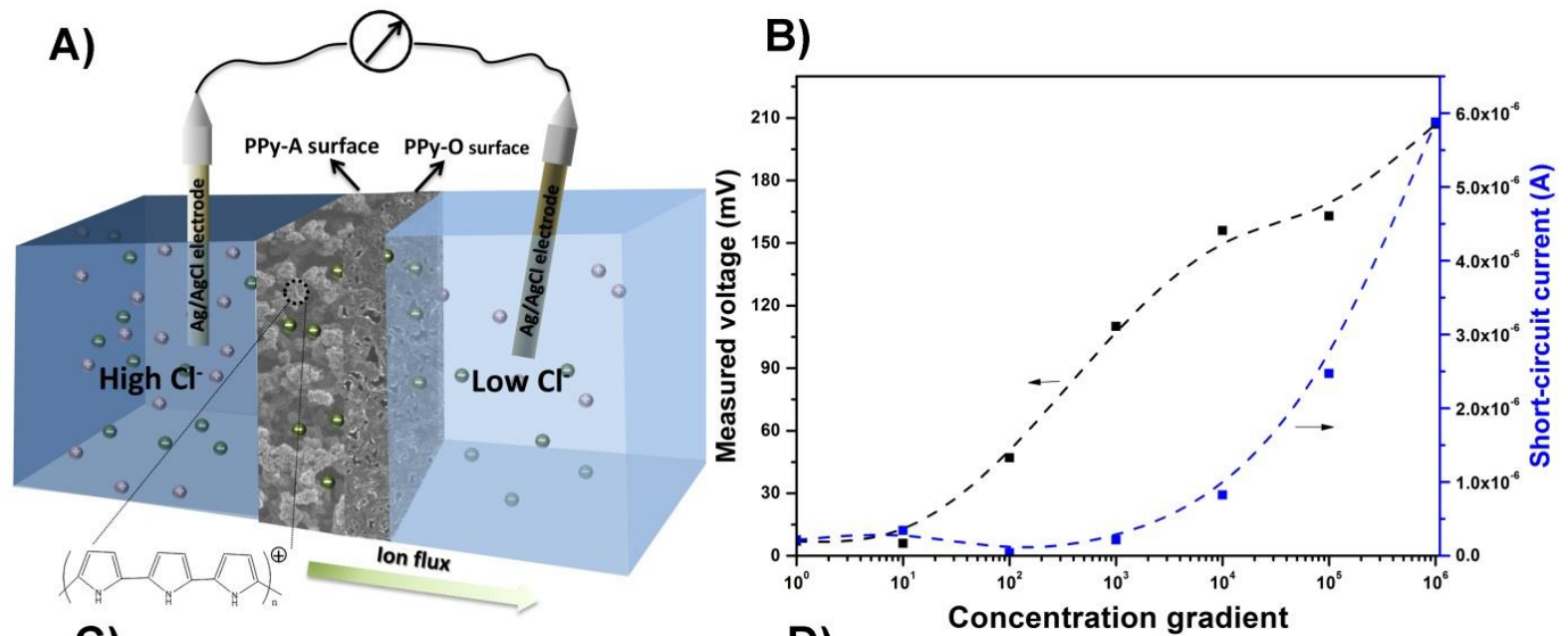

C)
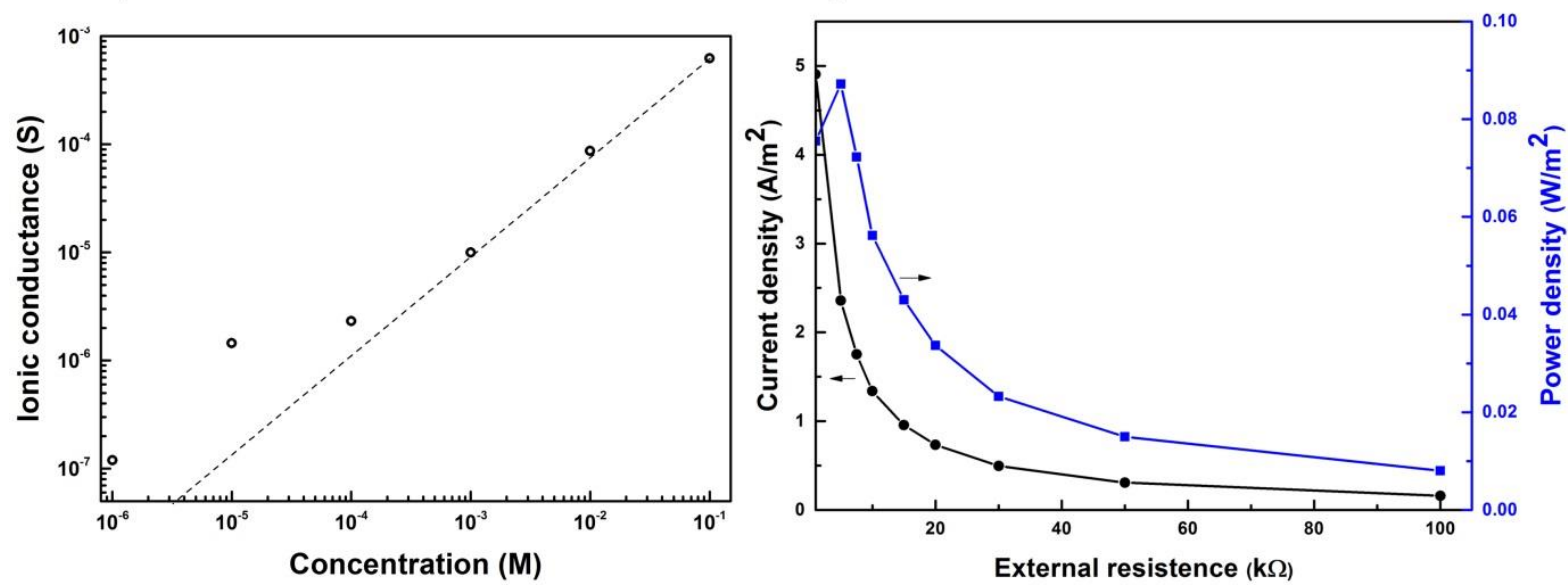

Figure 2 Energy conversion from salinity difference with a PPy membrane: A) Schematic illustration of the energy harvesting under a concentration gradient; B) Short circuit current and measured out voltage at the different concentration gradients, both the voltage and current increase with the salinity gradients; C) Ionic conductance of a PPy membrane in different concentrations of $\mathrm{KCl}$ solution; D) By mixing artificial seawater $(0.5 \mathrm{M} \mathrm{NaCl})$ and river water $(0.01 \mathrm{M} \mathrm{NaCl})$, the generated power can be output and supply an electric load.

The electrochemical oxidation and reduction of PPy involves both electron and ion-exchange processes [54]. In a PBS electrolyte with a matching ion concentration of body fluid, this membrane demonstrated an anodic peak at $0.5 \mathrm{~V}$ and cathodic peak $-0.25 \mathrm{~V}$ (Figure 3A), which is primarily due to ion transporting through the polymer to compensate the charges on 
the polypyrrole backbone [55]. These results clearly demonstrate that the ion transport of PPy can be governed by its redox state. The impedance plot of a PPy membrane is shown in Figure $3 \mathrm{~B}$, where the intercept at the real impedance ( $\left.Z^{\prime}\right)$ axis was $7.9 \Omega$, which is lower than the $12 \Omega$ reported for a free-standing PPy membrane prepared by electropolymerization, thus evidencing a high ionic conductivity of our membrane [42].

The ion conductance of this PPy membrane at the reduced or oxidised state was investigated. We applied a potential from -0.5 to $-1 \mathrm{~V}$ to trigger the reduction, and $0.1-0.5 \mathrm{~V}$ to trigger the oxidation. The ionic conductance (slope of the $I-V$ curve) increased with the applied transmembrane potential in $1 \mathrm{mM} \mathrm{KCl}$ solution (Figure 3C, 3D). This ion concentration is of the same order of magnitude as the extracellular fluid $\left(4 \mathrm{mM} \mathrm{K}^{+}\right)$[56]. When an oxidation potential of $0.5 \mathrm{~V}$ was applied, $-\mathrm{NH}-$ amine groups on the PPy chain was oxidised to $\mathrm{N}^{+}$as evidenced by the increased $\mathrm{N}^{+} /(-\mathrm{NH}-)$ ratio from 0.14 to 0.17 (XPS spectra, Figure $\mathrm{S} 10$ ). With an increase in oxidising potential or reducing potential, more ions are transported across the film, resulting in a higher streaming current [57]. The ionic conductance increased with the oxidation time (Figure S11), owing to the increased number of defects in the $\pi$-electron system that regulates the anions ingress onto the oxidised sites [19]. The ionic conductance of oxidised PPy $(0.5 \mathrm{~V})$ was $1.3 \times 10^{-5} \mathrm{~S}$, higher than that $8.6 \times 10^{-6} \mathrm{~S}$ at the reduced state $(-0.5 \mathrm{~V})$. A better ion transport in the oxidised PPy can be due to the tight packing of PPy at its oxidized state resulting in better ion selectivity [57]. Such tunable ionic conductance proves that this PPy membrane can be used as a smart electro-modulated membrane in the extracellular fluid. 

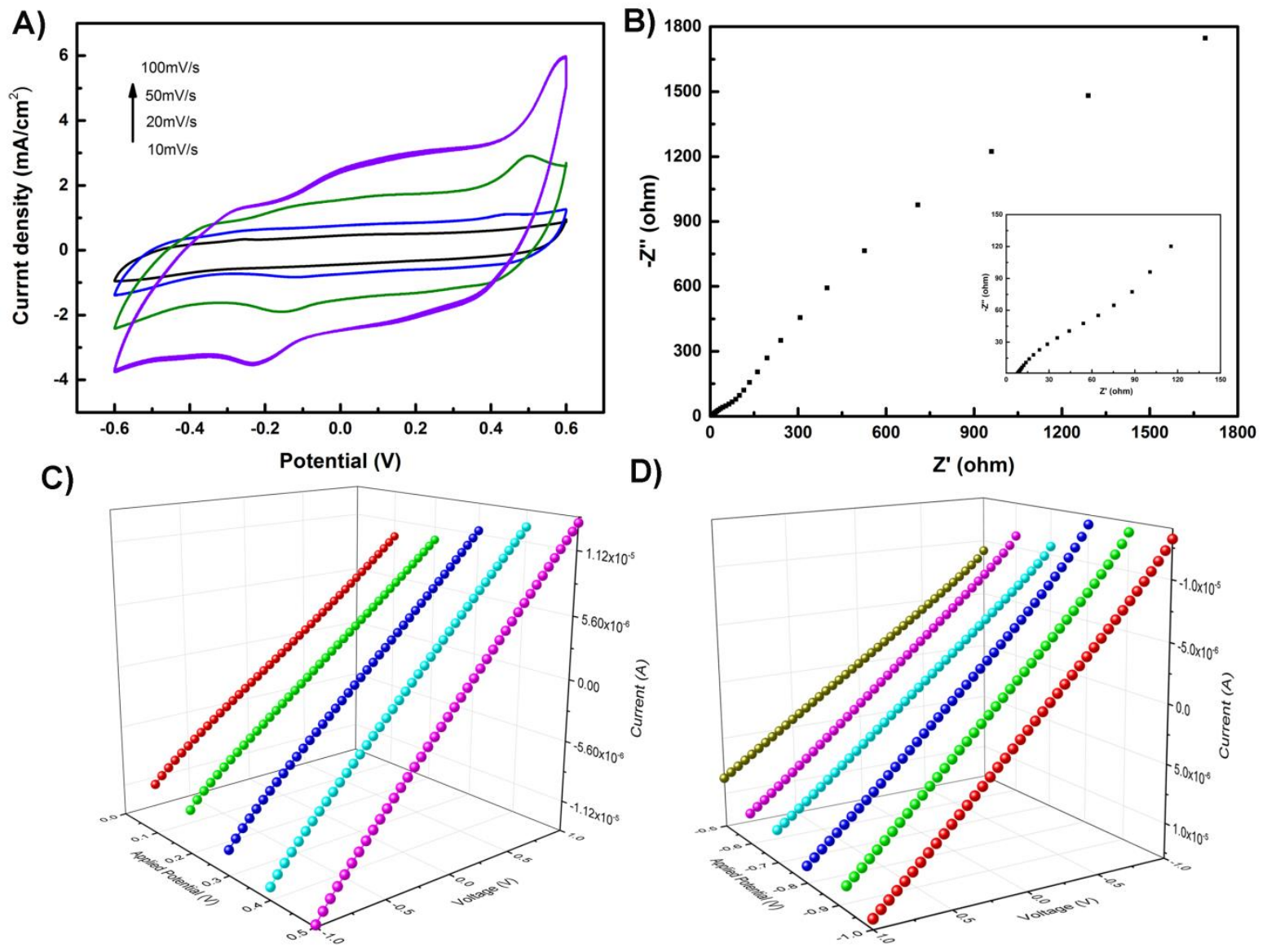

Figure 3 Electro-response profile of the PPy membrane: A) Cyclic Voltammograms of a PPy membrane at difference scan rates in a PBS solution; B) Nyquist plot of PPy in a PBS solution; C) Current-voltage response of the oxidised PPy membrane at different potentials in $1 \mathrm{mM} \mathrm{KCl}$ solution, oxidation time was 300s; D) Current-voltage response of the reduced PPy membrane at different potentials in $1 \mathrm{mM} \mathrm{KCl}$ solution, reduction time was 300s.

Smart biological devices that are interactive, programmable, and capable of seamless communication with surrounding tissues are highly desirable to evoke cell response [58]. The materials for use should be biocompatible or at least non-toxic. The cytocompatibility of PPy membrane was evaluated using human adipose-derived stem cells (hADSCs). As shown in the live/dead fluorescence staining (Figure 4A-C), hADSCs were well spread and reached 
high confluence at day 14 after seeding, showing the cytocompatibility of this film. In agreement with the fluorescence image, a flat, well spread cell morphology with filopodia attached tightly to the PPy granules; these cells also formed bridges over this highly porous substrate (Figure 4D). The total cell metabolic activity, characteristic of cell proliferation, increased significantly during the first 2 weeks, then stabilised (Figure 4E). These results demonstrate that this porous PPy membrane can well support adhesion and proliferation of hADSCs.
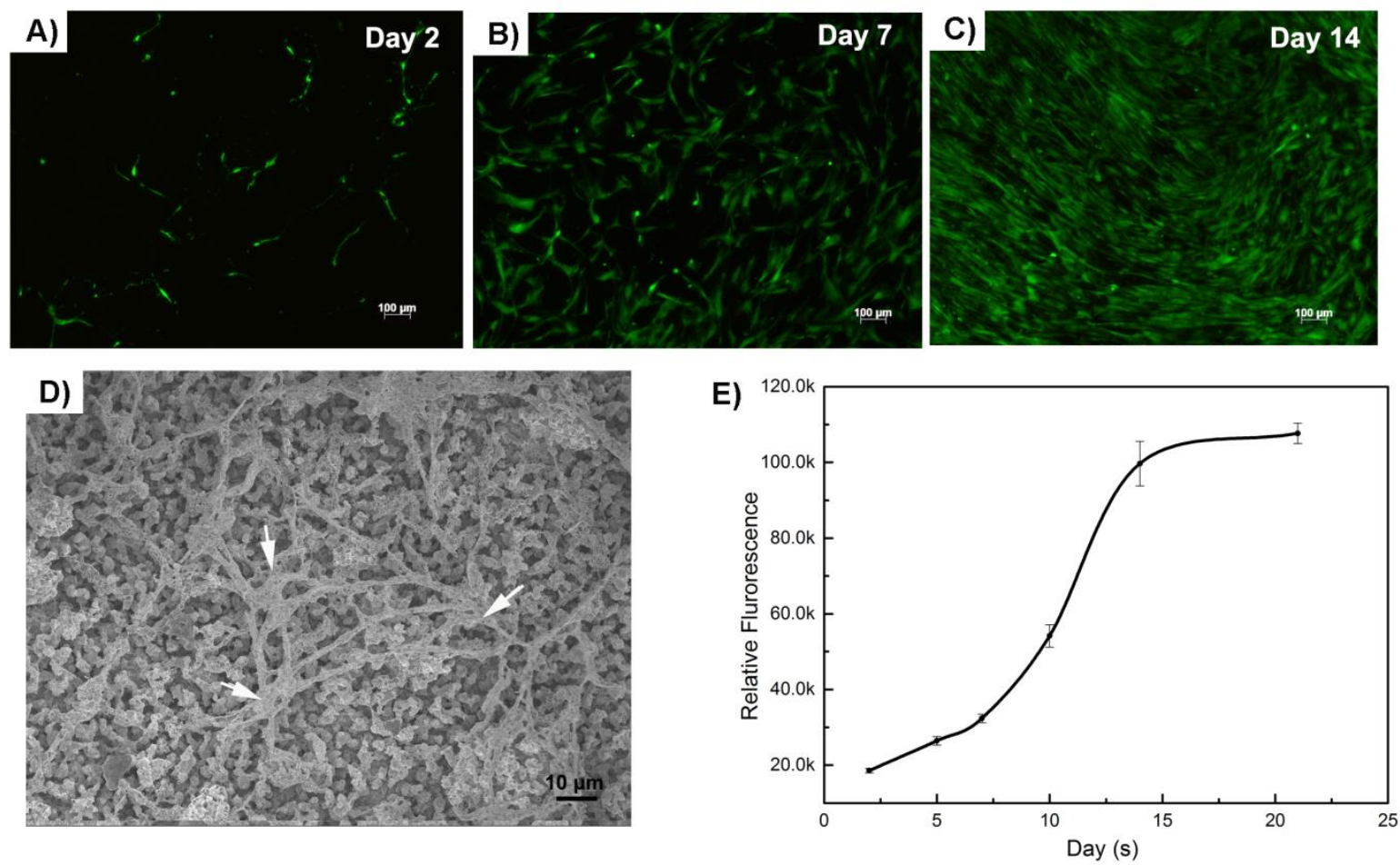

Figure 4 Cytocompatibility of the PPy membrane: Fluorescence micrographs of hADSCs on a PPy membrane at A) day 2, B) day 7 and C) day 14; D) SEM images of hADSCs (indicated by the arrows) on a PPy membrane at day 7; E) Growth curve of hADSCs on a PPy membrane during a 21 days period.

\section{Conclusions}


In summary, a smart polypyrrole membrane with an asymmetric structure has been developed via a self-assembly process. It demonstrates different wettability: hydrophobicity on the PPyaqueous surface and hydrophilicity on the PPy-oil surface; which can be ascribed to the asymmetric geometrical microstructure at these two faces. Its electrochemically tunable ionic conductance is ascribed to its charged backbone that regulates the ingress/egress of ions onto the redox sites. This membrane has demonstrated the capability to convert the salinity gradient into a streaming ionic current and realise an energy conversion, which can be ascribed to the ion permselectivity and preferred ion transportation within the asymmetric structure. Moreover, this membrane is a good substrate for Adipose-derived stem adhesion and proliferation. It can be deduced that this single component PPy membrane provides a platform to imitate biological ion transport by utilizing its asymmetric structure, and harvest energy from the stream of body fluid. This work may provide one step further towards the development of "smart" membrane based devices.

\section{Acknowledgments}

Funding from the Australian Research Council Centre of Excellence Scheme (CE 140100012) and National Science Foundation of China (51503214, 21504097) are gratefully acknowledged. Gordon G. Wallace is grateful to the ARC for support under the Australian Laureate Fellowship scheme (FL110100196). C. Y. acknowledges the support of a CSC scholarship from the Ministry of Education of P.R. China. The authors would like to thank Dr. Chee O. Too for his critical proof-reading. The authors thank Australian National Fabrication Facility-Materials node (ANFF) and UOW Electron Microscopy Centre for equipment use.

\section{Additional information}

The authors declare no competing financial interests.

\section{References}

[1] J. Feng, M. Graf, K. Liu, D. Ovchinnikov, D. Dumcenco, M. Heiranian, V. Nandigana, N.R. Aluru, A. Kis, A. Radenovic, Nature, 536 (2016), pp: 197-200.

[2] G. Xie, L. Wen, L. Jiang, Nano Res. 9 (2016), pp: 59-71.

[3] C. Cheng, G. Jiang, C.J. Garvey, Y. Wang, G.P. Simon, J.Z. Liu, D. Li, Sci. adv. 2 (2016) pp: e1501272.

[4] B. Yameen, M. Ali, R. Neumann, W. Ensinger, W. Knoll, O. Azzaroni, J. Am. Chem. Soc. 131 (2009), pp: 2070-2071. 
[5] W. Guo, H. Xia, F. Xia, X. Hou, L. Cao, L. Wang, J. Xue, G. Zhang, Y. Song, D. Zhu, Chem. Phys. chem, 11 (2010), pp: 859-864.

[6] A. Koçer, M. Walko, W. Meijberg, B.L. Feringa, Science, 309 (2005), pp: 755-758.

[7] Z.S. Siwy, S. Howorka, Chem. Soc. Rev.39 (2010), pp: 1115-1132.

[8] S.F. Buchsbaum, G. Nguyen, S. Howorka, Z.S. Siwy, J. Am. Chem. Soc. 136 (2014), pp: 9902-9905.

[9] L. Wen, X. Hou, Y. Tian, F.Q. Nie, Y. Song, J. Zhai, L. Jiang, Adv. Mater. 22 (2010), pp: 1021-1024.

[10] L. Wen, L. Jiang, Nati. Sci. Rev. 1 (2013), pp: 144-156.

[11] S.B. Lee, D.T. Mitchell, L. Trofin, T.K. Nevanen, H. Söderlund, C.R. Martin, Science, 296 (2002) pp: 2198-2200.

[12] A.L. Sisson, M.R. Shah, S. Bhosale, S. Matile, Chem. Soc. Rev. 35 (2006), pp: 12691286.

[13] B. Zhang, Y. Zhang, H.S. White, Anal. Chem. 76 (2004), pp: 6229-6238.

[14] X. Hou, W. Guo, L. Jiang, Chem. Soc. Rev. 40 (2011), pp: 2385-2401.

[15] G.G. Wallace, P.R. Teasdale, G.M. Spinks, L.A. Kane-Maguire, Conductive electroactive polymers: intelligent polymer systems, CRC press2008.

[16] C.E. Schmidt, V.R. Shastri, J.P. Vacanti, R. Langer, Proc. Nat. Acad. Sci. USA. 94 (1997), pp:8948-8953.

[17] G. Wang, L. Zhang, J. Zhang, Chem. Soc. Rev., 41 (2012), pp: 797-828.

[18] J.L. Bredas, G.B. Street, Accounts Chem. Res. 18 (1985), pp:309-315.

[19] C. Ehrenbeck, K. Jüttner, Electrochim. Acta, 41 (1996), pp:1815-1823.

[20] A. Partridge, C. Milestone, C. Too, G. Wallace, J. Membrane Sci. 132 (1997), pp: 245253.

[21] Q. Zhang, Z. Liu, K. Wang, J. Zhai, Adv. Funct. Mater. 25 (2015), pp: 2091-2098.

[22] B. Bao, J. Hao, X. Bian, X. Zhu, K. Xiao, J. Liao, J. Zhou, Y. Zhou, L. Jiang, Adv. Mater. (2017), pp: 1702926

[23] J. Pyun, K. Matyjaszewski, Chem. Mater. 13 (2001), pp: 3436-3448.

[24] Q. Yang, Z. Hou, T. Huang, J. Appl. Polym. Sci, 132 (2015), pp: 41615.

[25] G. Qi, Z. Wu, H. Wang, J. Mater. Chem. C. 1 (2013). pp: 7102-7110.

[26] K.-J. Ahn, Y. Lee, H. Choi, M.-S. Kim, K. Im, S. Noh, H. Yoon, Sci. Rep. 5 (2015), pp: 14097.

[27] H. Aizawa, J. Appl. Crystallogr. 42 (2009), pp: 592-596.

[28] Q.H. Yang, Z.Y. Tu, N.Y. Zhao, IOP Conference Series: Materials Science and Engineering, 137 (2016), pp: 012070.

[29] B. Tian, G. Zerbi, J. chem. phys. 92 (1990), pp: 886-3891.

[30] M.A. Chougule, S.G. Pawar, P.R. Godse, R.N. Mulik, S. Sen, V.B. Patil, Soft Nanosci. Letters, 1 (2011) pp: 6-10.

[31] L. Feng, S. Li, Y. Li, H. Li, L. Zhang, J. Zhai, Y. Song, B. Liu, L. Jiang, D. Zhu, Adv. Mater. 14 (2002), pp: 1857-1860.

[32] J. Song, H. Liu, M. Wan, Y. Zhu, L. Jiang, J. Mater. Chem. A, 1 (2013), pp: 1740-1744.

[33] J.W. Post, J. Veerman, H.V.M. Hamelers, G.J.W. Euverink, S.J. Metz, K. Nymeijer, C.J.N. Buisman, J. Membr. Sci, 288 (2007), pp: 218-230.

[34] J. Gao, W. Guo, D. Feng, H. Wang, D. Zhao, L. Jiang, J. Am. Chem. Soc. 136 (2014), pp: $12265-12272$.

[35] J. Hwang, S. Kataoka, A. Endo, H. Daiguji, Lab on a Chip, 16 (2016), pp: 3824-3832.

[36] D.K. Kim, C. Duan, Y.F. Chen, A. Majumdar, Microfluidics and Nanofluidics, 9 (2010), pp: $1215-1224$.

[37] H. C. Yeh, C. C. Chang, R.-J. Yang, RSC Advances, 4 (2014), pp: 2705-2714.

[38] X. Zhang, R. Bai, Langmuir, 19 (2003),pp: 10703-10709. 
[39] R. Skouri, F. Schosseler, J. Munch, S. Candau, Macromolecules, 28 (1995), pp: 197-210. [40] K. Kontturi, P. Pentti, G. Sundholm, J. Electroanal. Chem. 453 (1998),pp: 231-238.

[41] L. Poole-Warren, N. Lovell, S. Baek, R. Green, Expert review of medical devices, 7 (2010), pp: 35-49.

[42] C. Deslouis, T. El Moustafid, M. Musiani, B. Tribollet, Electrochim. Acta, 41 (1996), pp: 1343-1349.

[43] W. Guo, Y. Tian, L. Jiang, Accounts Chem. Res. 46 (2013), pp: 2834-2846.

[44] Y. Ito, M. Heydari, A. Hashimoto, T. Konno, A. Hirasawa, S. Hori, K. Kurita, A. Nakajima, Langmuir, 23 (2007), pp: 1845-1850.

[45] N. Gavish, K. Promislow, Phys. Rev. E. 94 (2016), pp: 012611.

[46] L. Shao, X. Cheng, Z. Wang, J. Ma, Z. Guo, J. Membr.Sci. 452 (2014), pp: 82-89.

[47] K. Boukerma, M. Mičušík, M. Mravčáková, M. Omastová, M.-J. Vaulay, P. Beaunier, M.M. Chehimi, Colloids and Surfaces A: Physicochemical and Engineering Aspects, 293 (2007), pp: 28-38.

[48] X. Zhu, Y. Zhou, J. Hao, B. Bao, X. Bian, X. Jiang, J. Pang, H. Zhang, Z. Jiang, L. Jiang, ACS nano, 11 (2017), pp: 10816-10824.

[49] Y. He, Z. Wang, J. Zhang, L. Wei, J. Mater. Chem. A, 5 (2017), pp: 21130-21133.

[50] S.R. Kwon, S.H. Nam, C.Y. Park, S. Baek, J. Jang, X. Che, S.H. Kwak, Y.R. Choi, N.R. Park, J.Y. Choi, Adv. Funct. Mater, 28 (2018), pp: 1705952.

[51] X. Wei, J. Liu, Frontiers of Energy and Power Engineering in China, 2 (2008), pp: 1-13.

[52] M. Masoodian, S. Jones, B. Rogers, Computer Human Interaction: 6th Asia Pacific Conference, APCHI 2004, Rotorua, New Zealand, June 29-July 2, 2004, Proceedings, Springer2005.

[53] J. Ji, Q. Kang, Y. Zhou, Y. Feng, X. Chen, J. Yuan, W. Guo, Y. Wei, L. Jiang, Adv. Funct. Mater. 27 (2017), pp: 1603623

[54] R. Ansari Khalkhali, W.E. Price, G.G. Wallace, React. Funct. Polym. 56 (2003), pp: 141-146.

[55] K.P. Vidanapathirana, M.A. Careem, S. Skaarup, K. West, Solid State Ionics, 154-155 (2002), pp: 331-335.

[56] B. Yilmaz, Z. Evis, Biomedical Nanomaterials: From Design To Implementation, Institution of Engineering and Technology, 2016, pp. 3-14.

[57] T. Hery, V.-B. Sundaresan, Energy Environ. Sci. 9 (2016), pp: 2555-2562.

[58] T.J. Rivers, T.W. Hudson, C.E. Schmidt, Adv. Funct. Mater, 12 (2002), pp: 33-37. 


\section{Highlights}

- A smart single component porous polypyrrole membrane with an asymmetric structure is fabricated via a facile self-assembly process.

- The polypyrrole membrane could be used for salinity gradient power generation.

- This membrane provides an electrochemically tuneable ionic conductance.

- This membrane is a biocompatible substrate for Adipose-derived stem cell adhesion and proliferation. 


\section{Supporting Information}

\section{A Smart Cyto-compatible Asymmetric Polypyrrole Membrane for Salinity Power}

\section{Generation}

Changchun $\mathrm{Yu}^{1}$, Xuanbo Zhu ${ }^{2}$, Caiyun Wang ${ }^{1 *}$, Yahong Zhou ${ }^{2 *}$, Xiaoteng Jia ${ }^{1}$, Lei Jiang ${ }^{2}$, Xiao Liu ${ }^{1}$, Gordon G. Wallace ${ }^{1 *}$

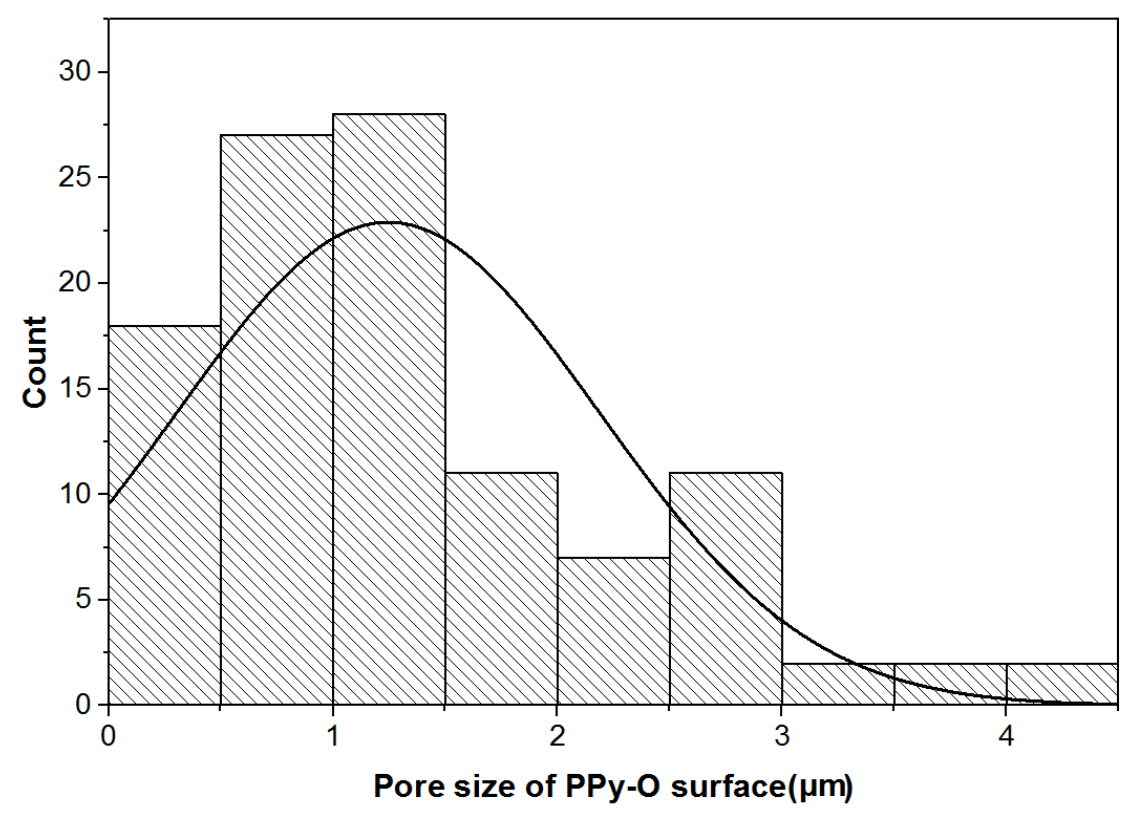

Figure S1 Statistical pore size distributions of PPy-O surface, calculated from 100 pores in the SEM observations
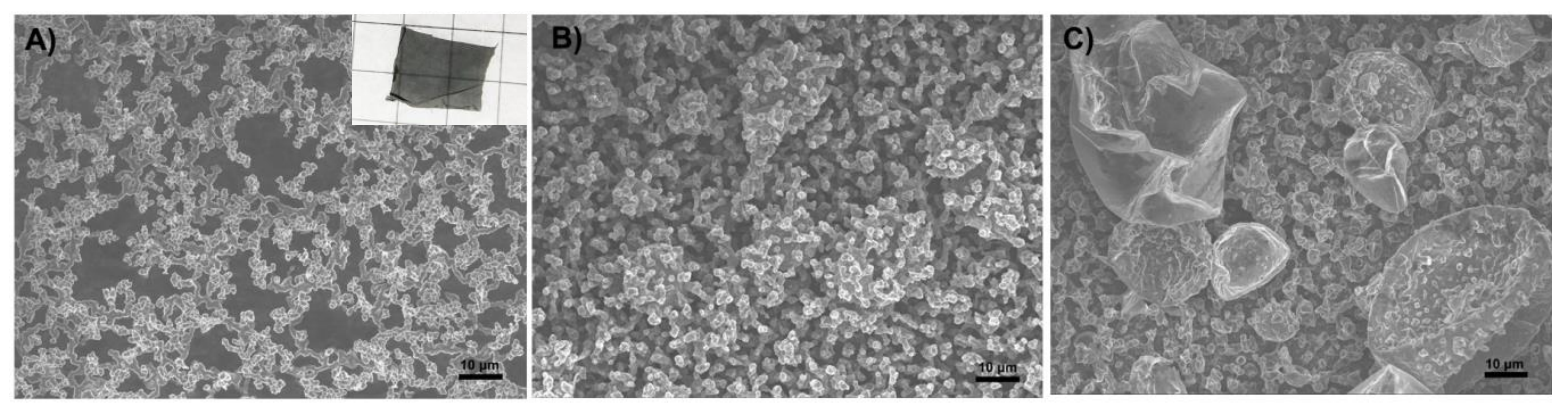
Figure S2 SEM images of the formed PPy from the solution containing Tween- 80 surfactant at a concentration of A) $0 \mathrm{~g} / \mathrm{L}$ (inset shows the film is very thin in black color); B) $2 \mathrm{~g} / \mathrm{L}$; and C) $4 \mathrm{~g} / \mathrm{L}$.

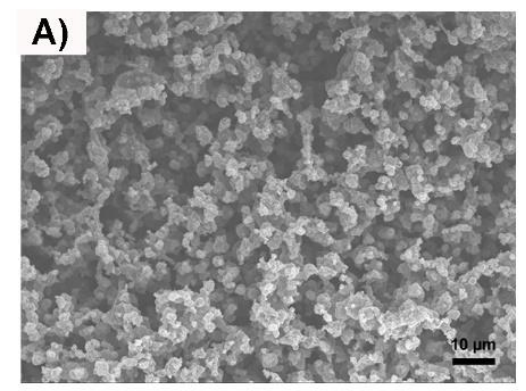

\section{B)}

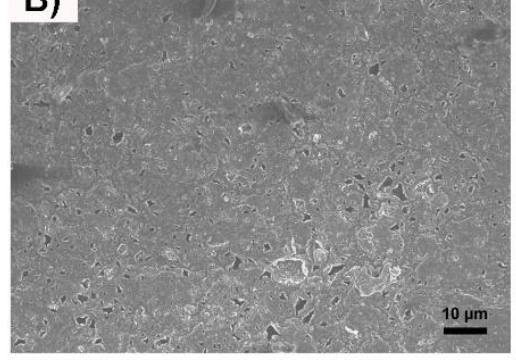

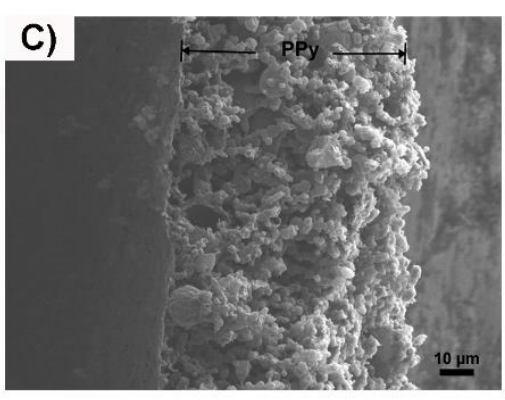

Figure S3 SEM images of the formed PPy in an ice bath with A) PPy-A surface, B) PPy-O surface and C) cross-section view

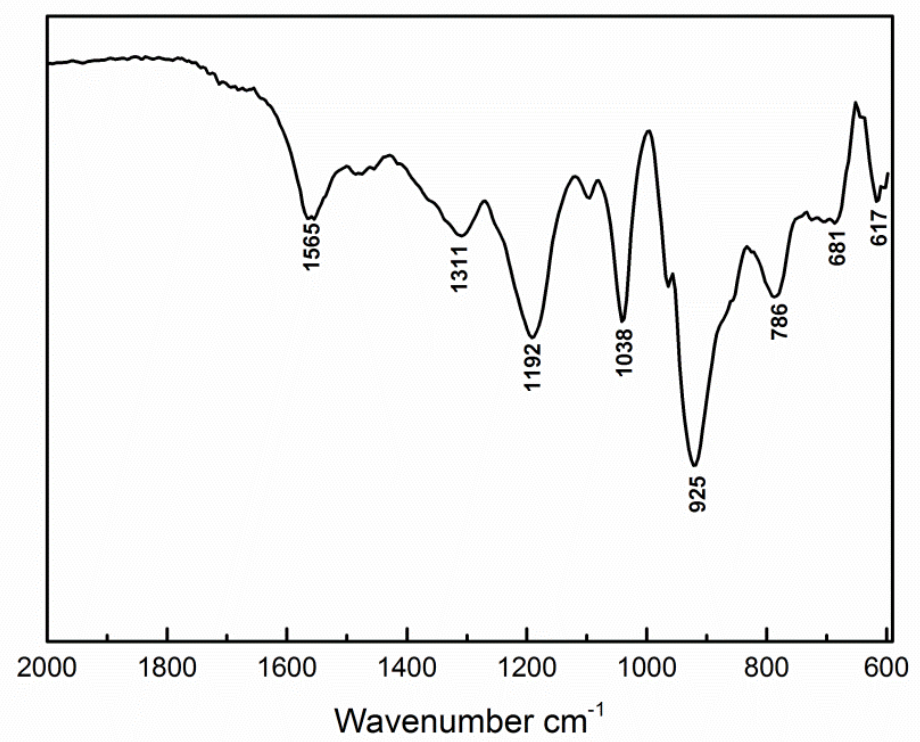

Figure S4 FTIR spectrum of a PPy membrane. 


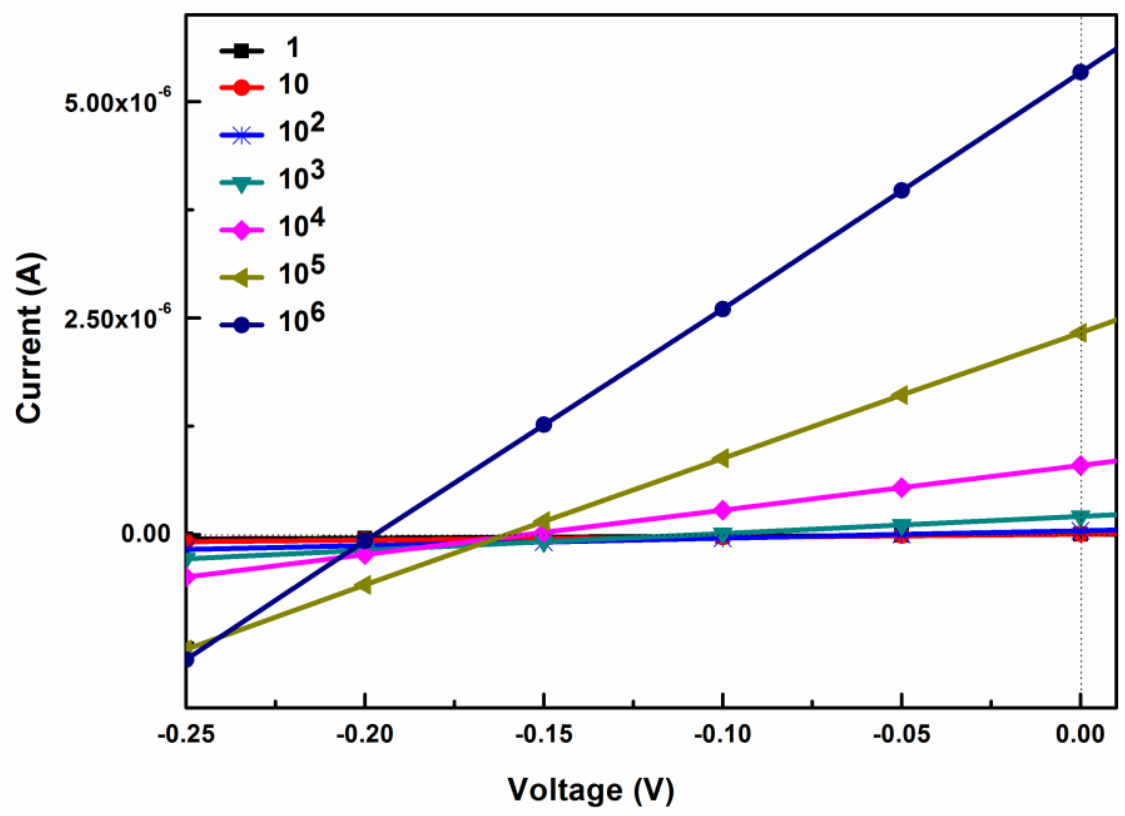

Figure S5 Current-voltage ( $I-V)$ response of a PPy membrane in $\mathrm{KCl}$ solution at different gradient ratios ranging from 1 to $10^{6}$.

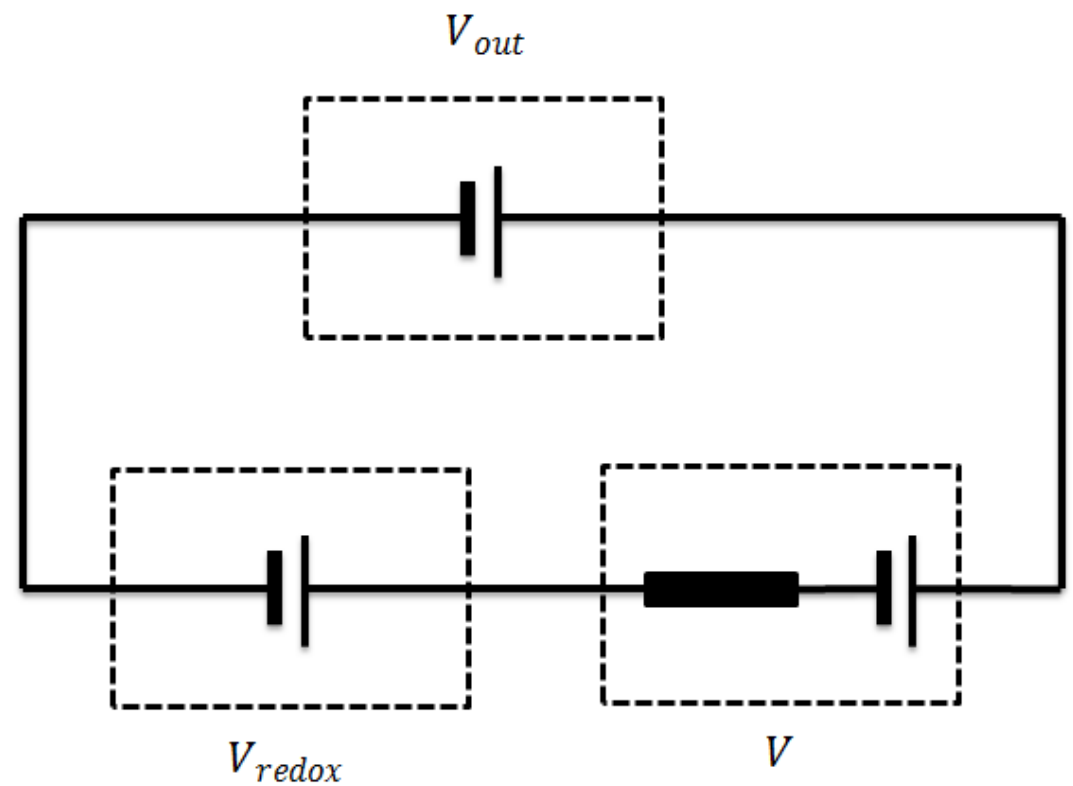

Figure S6 Equivalent circuit of the ion diffusion through the PPy membrane 


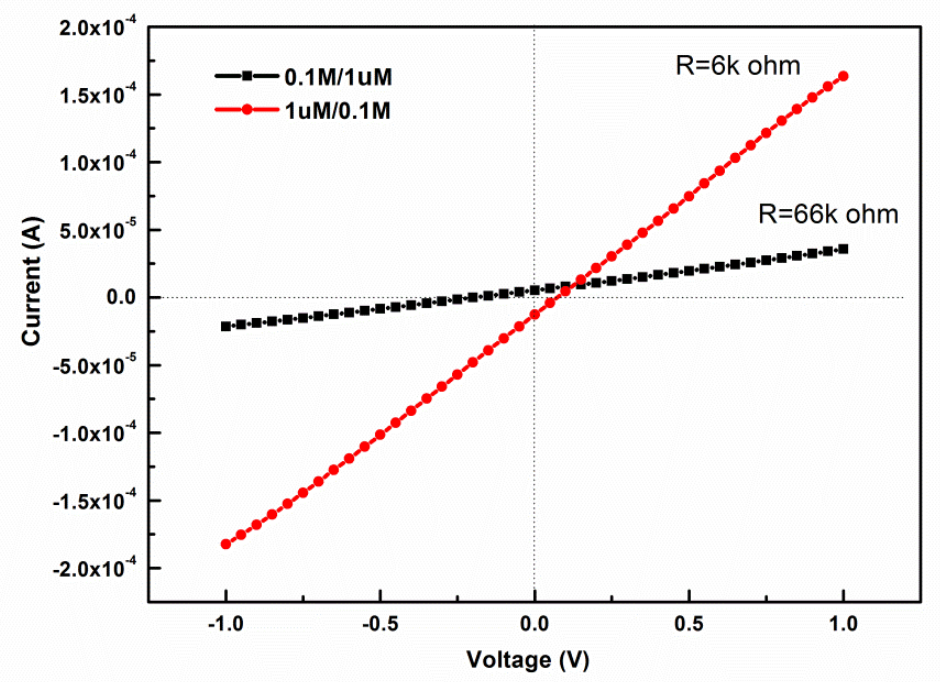

Figure S7 Internal resistance of the fluid system at the reversed concentration gradient. For the $0.1 \mathrm{M} / 1 \mu \mathrm{M}$ gradient, $\mathrm{U}$ and I were $163 \mathrm{mV}$ and $2.47 \mu \mathrm{A}$, respectively; in contrast to that $69 \mathrm{mV}$ and $-12 \mu \mathrm{A}$ obtained when the concentration gradient was reversed.

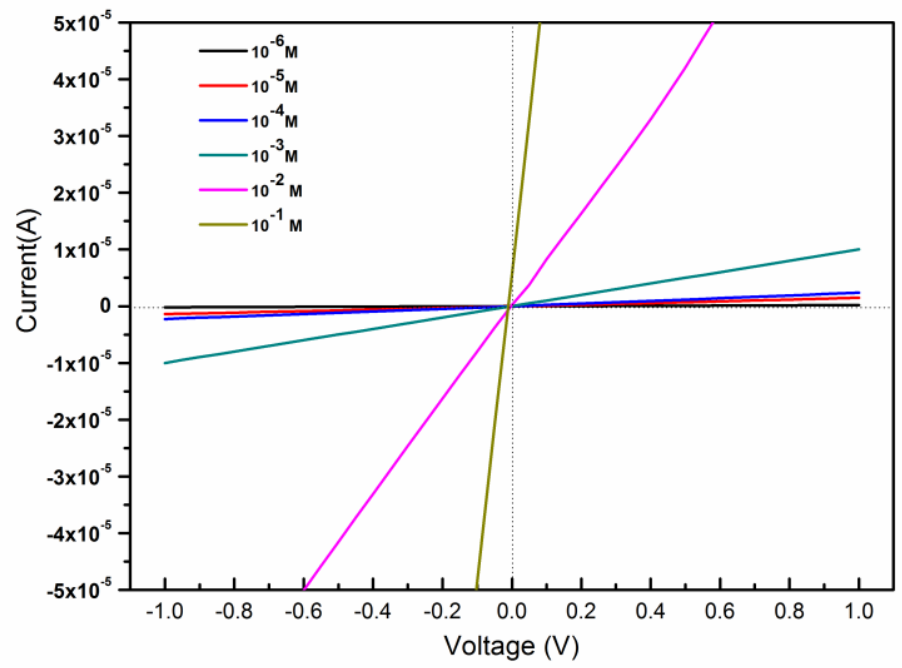

Figure S8 Current-voltage response of a PPy membrane in the $\mathrm{KCl}$ solution with the concentration from $10^{-6}$ to $10^{-1} \mathrm{M}$. 


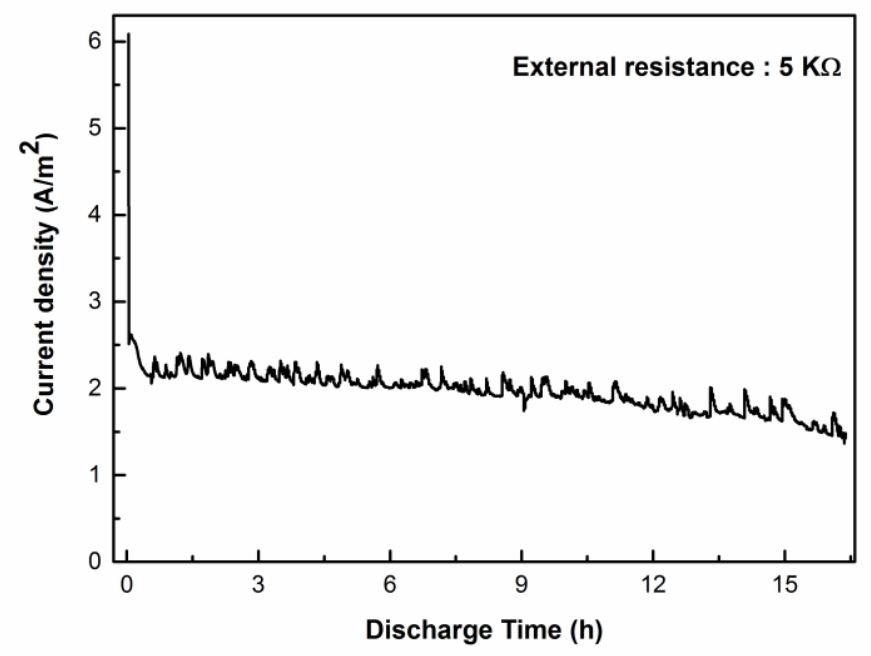

Figure S9 Current density of the PPy devices recorded during a monitoring time of 16 hours.

By mixing of artificial seawater $(0.5 \mathrm{M} \mathrm{NaCl})$ and river water $(0.01 \mathrm{M} \mathrm{NaCl})$, the device can generate an energy density of $1.4 \mathrm{Wh} / \mathrm{m}^{2}$.
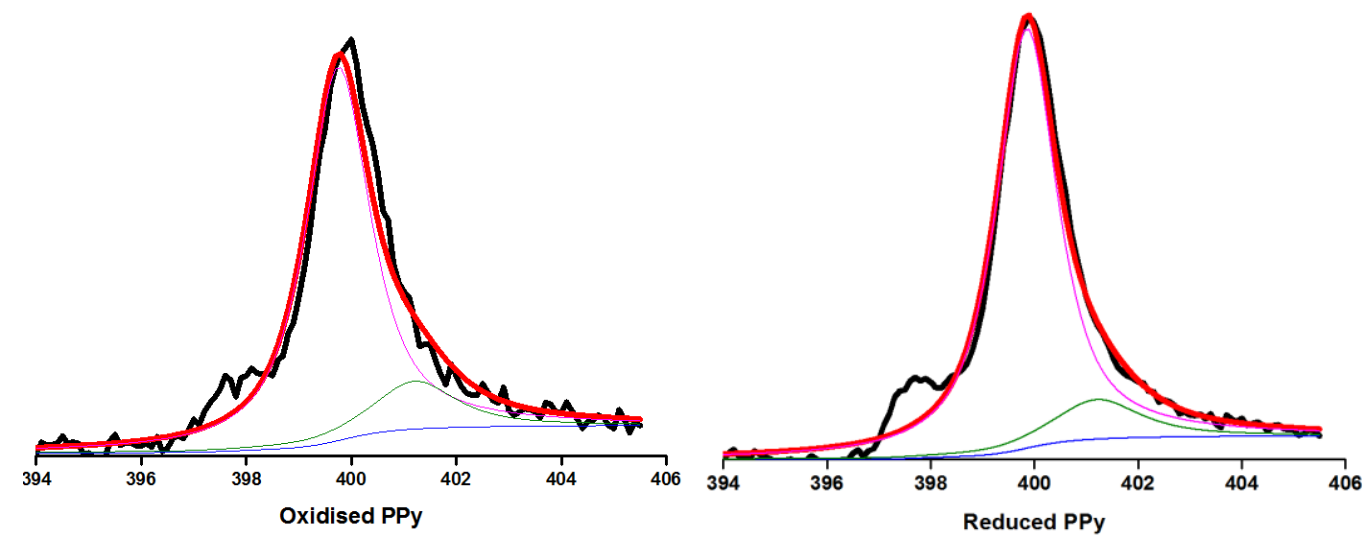

Figure S10 XPS N 1s spectra of oxidised PPy (left) and reduced PPy (right) with $-\mathrm{NH}-$ $(399.8 \mathrm{eV})$ and the positively charged nitrogen $\mathrm{N}^{+}(401.2 \mathrm{eV})$. 


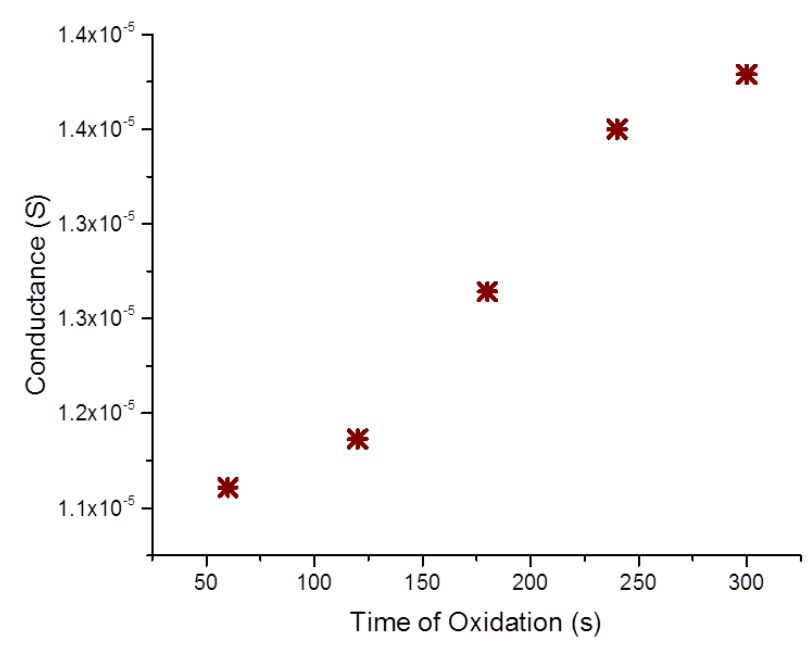

Figure S11 Ionic conductance of the PPy membrane at $0.5 \mathrm{~V}$ as a function of oxidation time (60 to $300 \mathrm{~s}$ ) in $1 \mathrm{mM} \mathrm{KCl}$ solution.

Movie S1 Movement of water droplets on the PPy-A surface of a PPy membrane.

Table S1 Measured out potential, redox potential and membrane potential of energy conversion system with different concentration gradients

\begin{tabular}{ccccc}
\hline $\begin{array}{c}\text { Concentration } \\
\text { gradient(M/M) }\end{array}$ & $10^{-6} / 10^{-3}$ & $10^{-6} / 10^{-2}$ & $10^{-6} / 10^{-1}$ & $10^{-6} / 1$ \\
\hline $\begin{array}{c}\text { Out potential } \\
(\mathrm{mV})\end{array}$ & 110 & 156 & 163 & 207 \\
\hline $\begin{array}{c}\text { Redox potential } \\
(\mathrm{mV})\end{array}$ & 90 & 93 & 103 & 114 \\
\hline $\begin{array}{c}\text { Membrane potential } \\
(\mathrm{mV})\end{array}$ & 20 & 63 & 60 & 93 \\
\hline
\end{tabular}


Table S2 Transference number for various combinations of concentrations

\begin{tabular}{ccccc}
\hline Concentration & $10^{-6} / 10^{-3}$ & $10^{-6} / 10^{-2}$ & $10^{-6} / 10^{-1}$ & $10^{-6} / 1$ \\
gradient(M/M) & & & & \\
\hline Transference number & 0.61 & 0.84 & 0.79 & 0.91 \\
\hline
\end{tabular}

Deduction of Debye screening length: Charged channels possess ion selective properties due to the electrical double layer, whose thickness is characterised by the Debye screening length

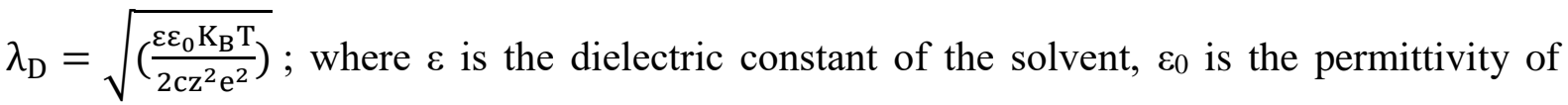
vacuum, $\mathrm{K}_{\mathrm{B}}$ is the Boltzmann constant, $\mathrm{T}$ is the absolute temperature, $\mathrm{c}$ is the concentration of ionic solution, $\mathrm{z}$ is the valence of the ion, and $\mathrm{e}$ is the electron charge. 